\title{
Evaluation of the Performance of Annular Composite Fin using ANSYS
}

\author{
Ashish Giri \\ Lecturer \\ RCET, BHILAI
}

\author{
S.A.K. Jilani \\ S.A.K. Jilani \\ Professor \\ RCET, BHILAI
}

\begin{abstract}
Often fins are required to operate under the hostile environments i.e., high temperatures and corrosion environment. Due to this the life of the fin is questionable. To protect it, an anti-hostile coating material is used like Zinc, Zink alloys, Silver, $\mathrm{Cu}, \mathrm{Mg}$ etc, there by the life of the fin can be increased and efficiency also.

In this paper the Gardener's expression for one material fin is deduced for a bi-material fin, by changing only the value of one parameter (temperature distribution). The efficiency of the fin is calculated for various thickness of coating material Zinc and Zinc Alloy. The efficiencies are compared with the normal fin.
\end{abstract}

The study also includes the effect of the temperature variation, which exists along the fin, from base to tip and convective heat transfer coefficient variation on efficiency of the fin.

Numerical simulations have been done using ANSYS software by varying thickness of Zinc and its alloy for a normal fin. The simulation results have been compared with the analytical solutions.

\section{General Terms}

$\mathrm{C}=$ Fin thickness $(\mathrm{m})$

$\mathrm{h}=$ Convection coefficient $\left(\mathrm{w} / \mathrm{m}^{2} \mathrm{k}\right)$

$\mathrm{I}_{0}=$ Modified Bessel function of the first kind and of order zero

$I_{1}=$ Modified Bessel function of the first kind and of order one.

$\mathrm{K}_{0}=$ Modified Bessel function of the second kind and of order zero.

$\mathrm{K}_{1}=$ Modified Bessel function of the second kind and of order one.

$\mathrm{R}_{\mathrm{b}}=$ Fin base radius $(\mathrm{m})$

$\mathrm{R}_{\mathrm{c}}=$ extremity radius $(\mathrm{m})$

$\mathrm{z}=$ Abscissa

$\delta=$ Temperature distribution parameter for a one material fin $\left[\mathrm{m}^{-1}\right]$

$\delta_{2}=$ Temperature distribution parameter for a bi-material fin $\left[\mathrm{m}^{-1}\right]$

$\eta_{\mathrm{b}}=$ Basic fin efficiency $(\%)$

$\eta_{\mathrm{c}}=$ Coated fin efficiency $(\%)$

\section{Keywords}

Annular fin, Composite fin, Efficiency of composite fin, ANSYS simulation of annular fin.

\section{INTRODUCTION}

The rate of heat transfer through a solid can be increased by using the extended surfaces called fins. An extended surface configuration is generally classified as a straight fin and annular fin. The terms straight fin is applied to the extended surface attached to a wall and an annular fin is one that is circumferentially attached to a cylindrical surface. In extended surface heat transfers by conduction within its boundaries, as well as convection between its boundaries and the surroundings. Radial or concentric annual fins are one of the most common choices for enhancing the rate of heat transfer from circular tubes. The evaluation of convective heat transfer from fins to the air has been carried out in the case of 'annular' fins subjected to an air flow parallel to the fin surface. These fins are used in compact heat exchangers and finned tube heat exchangers. In general annular fins cross section varies with radius, this is called as profile. Different fin profiles are rectangular, triangular, trapezoidal, hyperbolic and parabolic. Rectangle profile fins having constant thickness from base to tip are quite common in usage.

Fins are generally used on the surface where the heat transfer coefficient is low. Often fins are required to operate under the hostile environments i.e., high temperatures and corrosion environment. Due to this the life of the fin is questionable. To protect the fin from the hostile environment an anti-hostile coating material is coated, there by the life of the fin can be increased. Such an extended surface composed of two or more materials are can be referred as a composite fin. The composite fins can be constructed by coating or laminating a second material on the core material. The different coating materials are Zinc, Aluminum, Chromium, Silicon, Manganese, Copper, Silver, Nickel, Stainless Steel, Lead, Iron, Molybdenum, Tungsten, Cadmium, Aluminum Oxide, Aluminum Silicate, Magnetite, Chrome Magnetite, Chrome brick, Gold, Tin and the alloys of Aluminum, Zinc, Tin, Lead and Copper.

Coating of such materials and their alloys protects the core material from the environmental effects, like highly polluted air (air containing gases such as $\mathrm{CO}, \mathrm{CO}_{2}, \mathrm{SO}_{2}, \mathrm{SO}_{3}, \mathrm{NH}_{3}$ etc.) in industrial areas, frequency and intensity of rain fall, frequency and duration of dew and mist, moisture content of the air, the Chloride content of sea air, water containing chemical pollutants, and marine water effects on the coating materials. Due to these effects the coating materials are destroyed by corrosion. Therefore the core material is protected.

The present work is an attempt to investigate the effect of high thermal conductivity coating materials, viz., Zinc and Zinc alloy on the efficiency of the fin at various design conditions.

\section{METHEDOLOGY}

\subsection{Physical Model}

The sketch of an annular composite fin with rectangular profile is shown in the fig. 2.1, with the coordinate system and dimensions that are adopted in the development formulations of the problem. 


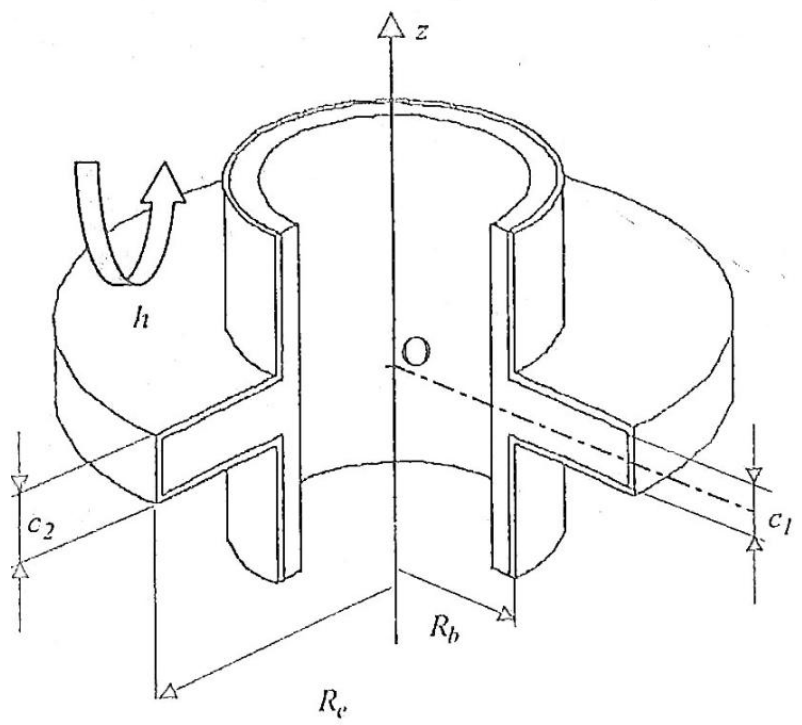

Fig 1: physical model and coordinate system of an annular composite fin with rectangular profile ${ }_{[1]}$

The inner region of the fin is designated as region 1, which will be indicated by the subscript ' 1 ' and the outer or cladding region is designated as region ' 2 '. The fluid flow temperature is taken as constant. The heat transferred through the fin tip is negligible. Since the geometry and the boundary conditions are symmetric about the centerline of the fin. The analysis was made only for the upper half region of the fin. In order to simplify the analysis $r$-axis is selected along the centerline of the fin (radial direction of the fin) and the $\mathrm{Z}$-axis along the transverse axis of the fin (along the axis of the cylindrical tube).

\subsection{Governing Equations}

S Lalot, C. Tournier, M. Jensen have found the following expression for the efficiency of an annular composite fin shown in fig.2.1, in which heat is supplied at the base with constant temperature ' $T_{b}$ '. The temperature is a function of two space coordinates i.e., ' $r$ ' the radius and ' $z$ ' the thickness.

(a) Efficiency of coated fin ${ }_{[1]}$

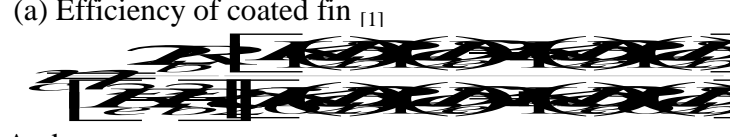

And

(b) Efficiency of basic fin

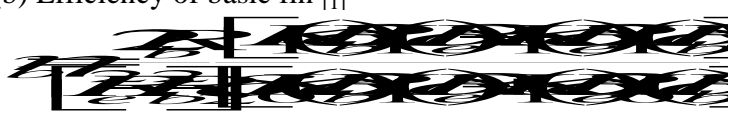

\subsection{Material selection}

In the present study, the core material is assumed as steel, and the coating materials are assumed as Zinc and Zinc alloy ( $\mathrm{Zn}$ $95.37 \%, \mathrm{Al} 4.3 \%, \mathrm{Mg} 0.08 \%, \mathrm{Cu} 0.25 \%$ ), due to their high thermal conductivity than core material.

\subsection{Modeling of annular fin using ANSYS}

ANSYS 11.0 version software has been used to model and analyze the annular fin (basic fin and coated fins).

\section{RESULT AND DISCUSSION}

The following results were obtained from the analysis

\subsection{Influence of the Convection Coefficient on the Efficiency Ratio}

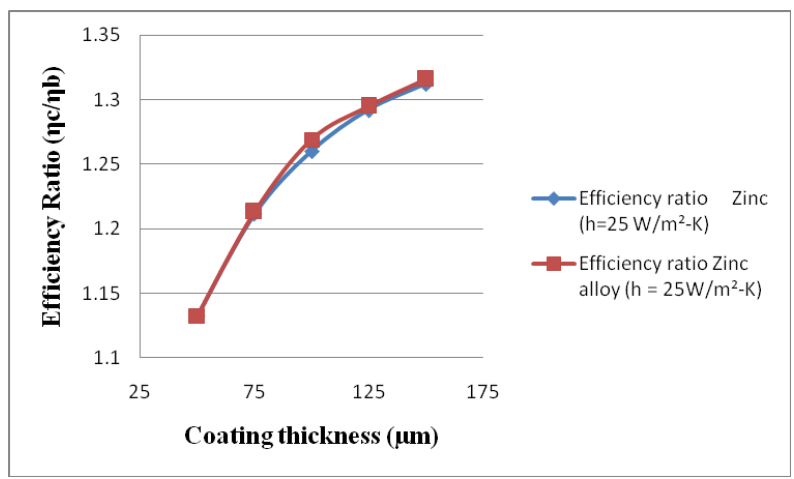

Fig 2

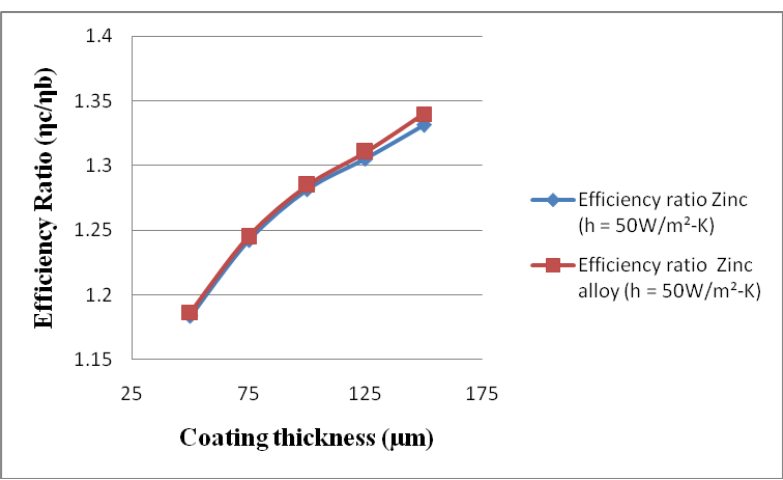

Fig 3

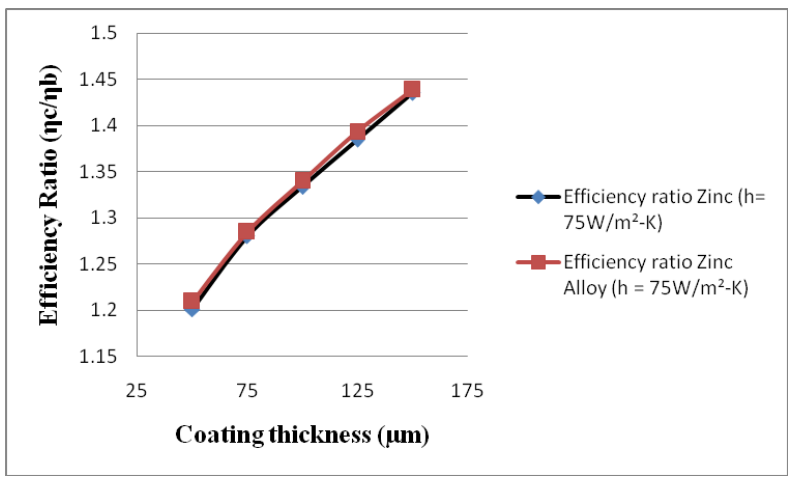

Fig 4

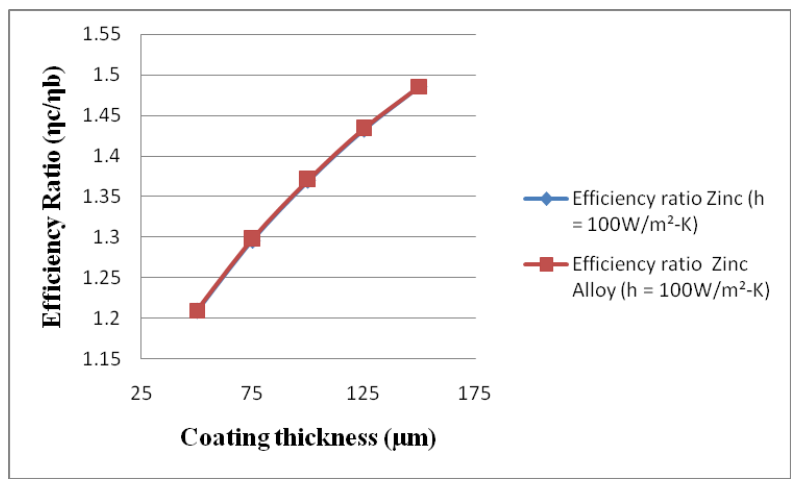

Fig 5 
For $\mathrm{h}=25 \mathrm{~W} / \mathrm{m}^{2} \mathrm{~K}, \mathrm{~h}=50 \mathrm{~W} / \mathrm{m}^{2} \mathrm{~K}, \mathrm{~h}=75 \mathrm{~W} / \mathrm{m}^{2} \mathrm{~K}$ and $\mathrm{h}=$ $100 \mathrm{~W} / \mathrm{m}^{2} \mathrm{~K}$. While studying the influence of convection coefficient the other variable such as fin base radius $\left(R_{b}\right)$, fin tip radius $\left(\mathrm{R}_{\mathrm{e}}\right)$,radius ratio $\left(\mathrm{R}_{\mathrm{e}} / \mathrm{R}_{\mathrm{b}}\right)$ and core thickness $\left(\mathrm{C}_{1}\right)$ were kept constant. The following observations were made from the graphs shown in fig. 2 to fig. 5

(i) It is observed that, the fin efficiency ratio increases with an increase in the coating thickness.

(ii) It is observed that, the efficiency ratio increases with increase in convection coefficient.

(iii) It is also observed that, the efficiency ratio of the Zinc alloy coated fin is slightly greater than the Zinc coated fin.

\subsection{Influence of the Radius Ratio on the Efficiency Ratio}

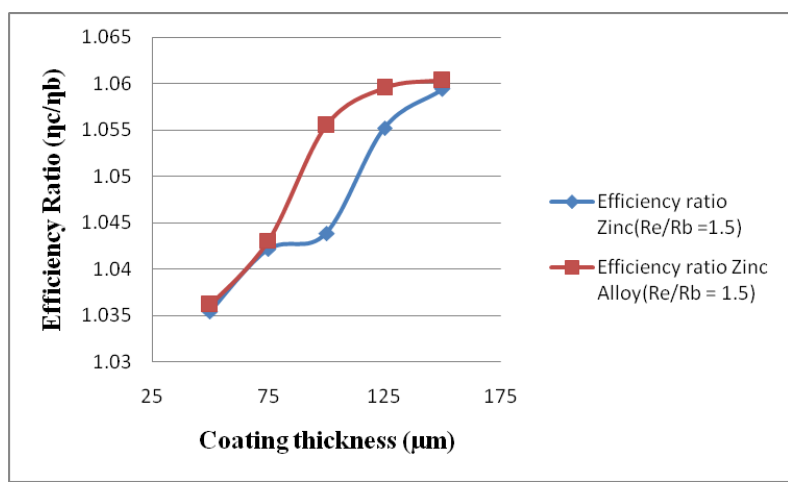

Fig 6

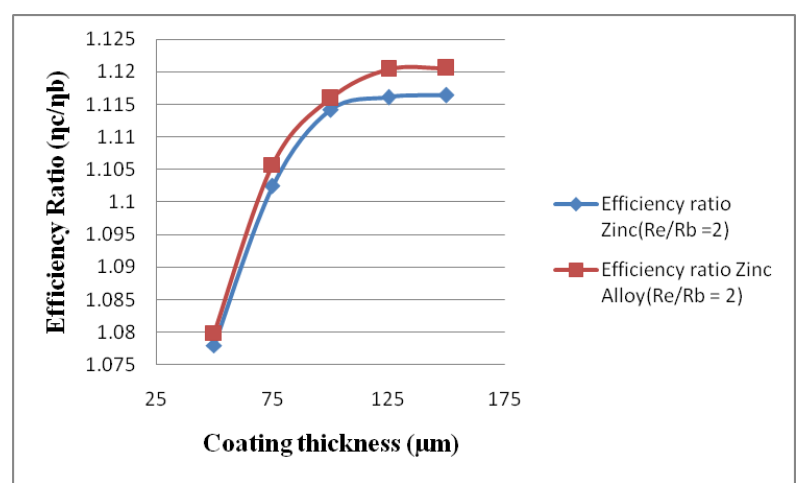

Fig 7

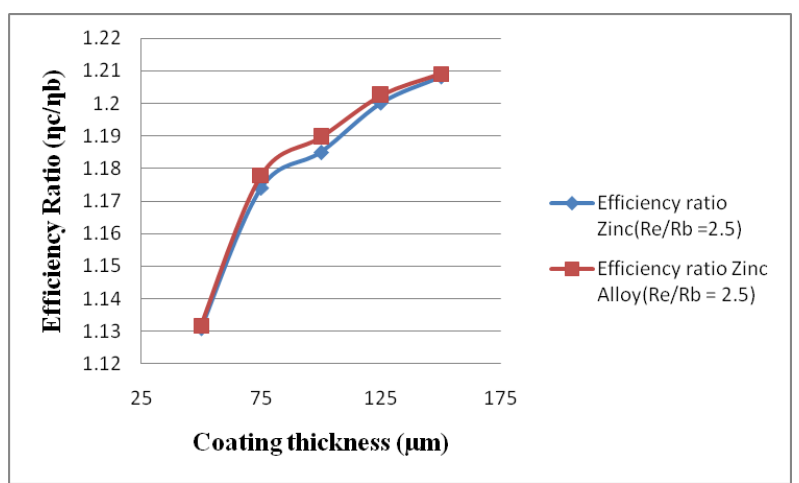

Fig 8

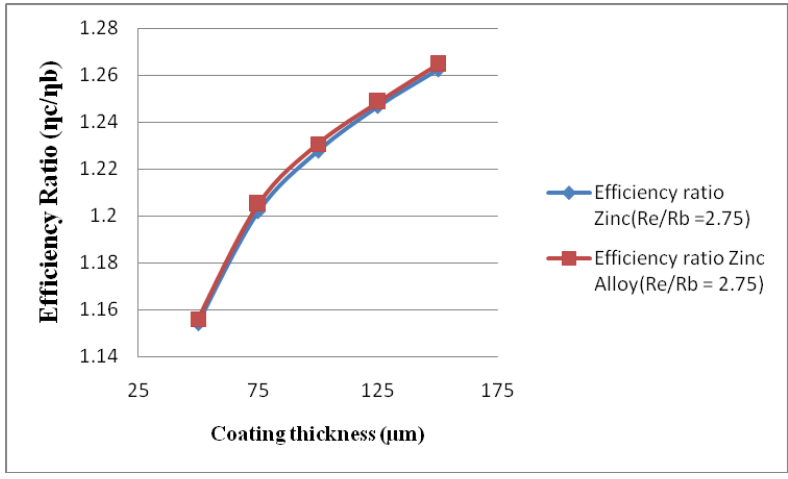

Fig 9

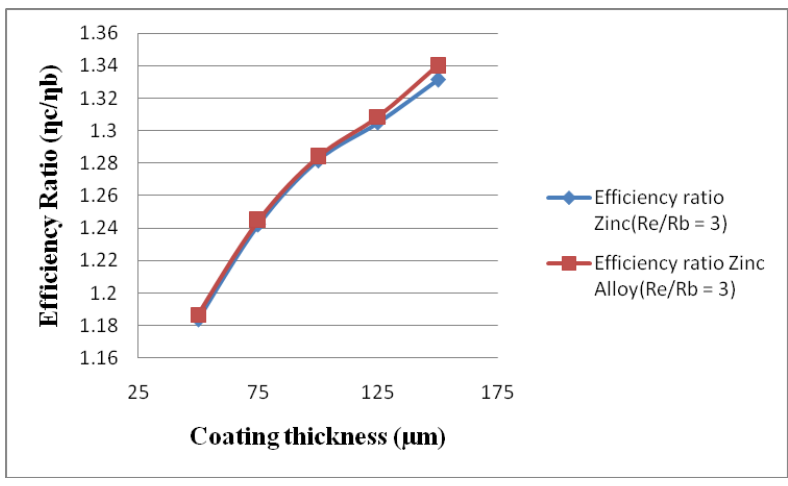

Fig 10

For $\mathrm{R}_{\mathrm{e}} / \mathrm{R}_{\mathrm{b}}=1.5, \mathrm{R}_{\mathrm{e}} / \mathrm{R}_{\mathrm{b}}=2, \mathrm{R}_{\mathrm{e}} / \mathrm{R}_{\mathrm{b}}=2.5, \mathrm{R}_{\mathrm{e}} / \mathrm{R}_{\mathrm{b}}=2.75$ and $\mathrm{R}_{\mathrm{e}} / \mathrm{R}_{\mathrm{b}}$ $=3$. While studying the influence of radius ratio, the other variables such as base radius $\left(R_{b}\right)$, convection coefficient $(h)$ and core thickness $\left(\mathrm{C}_{1}\right)$ were kept constant.

It is observed from graphs shown in the figs. From 4.5 to 4.9 that, For a given base radius $\left(R_{b}\right)$, the length of the fin is proportional to the radius ratio. When the radius ratio increases, the efficiency of the basic fin decreases and the composite fin increases, which gives high efficiency ratio.

\section{CONCLUSION}

In this paper, an attempt in made to study the efficiency of annular fins with rectangular profile, when coated with Zinc and Zinc alloy, under two dimensional steady state conditions. In this regard, the following conclusions were drawn.

1. The efficiency of the fin decreases with increase in convection coefficient.

2. The efficiency of the fins increases with increase in core thicknessCoating with a high thermal conductivity increases the efficiency of the fins.

3. Finally from the analysis the efficiency and corresponding the efficiency ratio of the Zinc Alloy coated fin is slightly greater than the Zinc coated fin

\section{ACKNOWLEDGMENTS}

I wish to express deep gratitude thanks to Dr. R.L. Himte Head of the Department of Mechanical Engineering Rungta college of Engineering and Technology,

I am very much thankful to our beloved Principal Dr. Prasanna Kumar for providing facilities to complete this project.

Finally, I am very much Thankful to the Rungta college of Engineering \& Technology. 


\section{REFERENCES}

[1] Lalot. S. et.al. "Fin efficiency of annular fins made of two materials" International Journal, Heat and Mass Transfer, Vol. 42, 1999, pp. 3461-3467.

[2] Barker, J.J., "The Efficiency of Composite Fins", Nuclear Science and Engineering, Vol.3, 1958, pp. 300312.

[3] K.A. Gardner "Efficiency of extended surface", Transactions of the ASME Nov. 1945. Pp. 621-631.

[4] Ullmann, A; and Kalman, H, "Efficiency and optimised Dimensions of Annular fins of different cross section shapes", International Journal of Heat and Mass transfer, Vol.32, No.6, 1989, pp. 1105-1110.

[5] Duffin, R.J., and Melain, D.K. "Optimum shape of a cooling fin on a convex cylinder" Journal of Mathematical Mechanics, Vol. 17, 1968, pp. 769-784.

[6] Mokhimer E.M.A., "Performance of Annular fins with different profiles subject to variable heat transfer coefficient" International Journal of Heat \& Mass Transfer Vol. 45, No.17, pp. 3631-3642.
[7] Campo, Antoni, Stuffle, "Symbolic Mathematics for the Calculation of thermal efficiencies and tip temperature in Annular fins of Uniform Thickness" International Journal Heat \& Mass Transfer, Vol. 40, No. 42, Jan. 1997 pp. 490-492.

[8] Harper, D.R. Brown, W.B., "Mathematical Equations for Heat Conduction in the fins of air-cooled Engines" National Advisory Committee for Aeronautics, Report No. 158, 1922.

[9] Murry W.M., "Heat Dissipation through an Annular Disk or Fin of Uniform Thickness", Journal of applied Mech. Trans. ASME, Vol. 60, 1938, pp. A-78.

[10] Mathewson, C.H., "Zinc, The metal its alloys and compounds" Reinhold Publishing Corporation - New York, $2^{\text {nd }}$ Edn., 1960.

[11] Title, C.W., "Boundary Value Problems in composite Media Quasi-Orthogonal Function", Journal of Applied Physics, Vol.36, No.4, 1965, pp. 1486-1488 